\title{
Short communication: Short-time freezing does not alter the sensory properties or the physical stability of ultra-high-temperature hydrolyzed-lactose milk
}

\author{
R. Bottiroli, ${ }^{1,2} \oplus$ C. Zhang, ${ }^{3} \odot$ E. Aprea, ${ }^{1,4 *} \odot$ V. Fogliano, ${ }^{5}$ K. Hettinga, ${ }^{3} \odot$ and F. Gasperi ${ }^{1,4} \oplus$ \\ ${ }^{1}$ Department of Food Quality and Nutrition, Research and Innovation Centre, Fondazione Edmund Mach (FEM), via E. Mach 1, \\ 38010 San Michele all'Adige, TN, Italy \\ ${ }^{2}$ Department of Agriculture and Food Science, University of Naples, Federico II, 80055 Portici, NA, Italy \\ ${ }^{3}$ Dairy Science and Technology Group, Wageningen University, PO Box 8129, 6700 EV Wageningen, the Netherlands \\ ${ }^{4}$ Center Agriculture Food Environment, University of Trento/Fondazione Edmund Mach, via E. Mach 1, 38010 San Michele all'Adige, TN, Italy \\ ${ }^{5}$ Food Quality and Design Group, Wageningen University, PO Box 8129, 6700 EV Wageningen, the Netherlands
}

\section{ABSTRACT}

In this study, the effect of milk freezing was studied, focusing on the changes in $1 \%$ and $3 \%$ fat UHT hydrolyzed-lactose milk after slow- $\left(-20^{\circ} \mathrm{C}\right)$ and fastrate freezing $\left(-80^{\circ} \mathrm{C}\right)$ for $72 \mathrm{~h}$. Changes on the sensory properties were first assessed by discriminant analysis (triangle test), and then by volatile organic compounds and color analysis. The milk emulsion stability was characterized by optical centrifugation, particle size analysis, and confocal microscopy. The sensory panel was not able to distinguish the milk subjected to freezing from the control $\left(72 \mathrm{~h}\right.$ at $\left.20^{\circ} \mathrm{C}\right)$. The volatile organic compounds and color analysis demonstrated that both freezing rates did not cause any significant changes in the milk aroma or color characteristics. The results of physical properties confirmed that short-time freezing did not lead to a distinct destabilization, except for a slight increase in the mean particle diameter at $-80^{\circ} \mathrm{C}$. Taking all the results together, UHT hydrolyzed-lactose milk was not significantly altered during the operation of freezing and thawing and, therefore, short-time freezing at both $-20^{\circ} \mathrm{C}$ and $-80^{\circ} \mathrm{C}$ can be used for milk storage without altering the product.

Key words: freezing, sensory property, aroma compound, physical stability, hydrolyzed-lactose milk

\section{Short Communication}

Freezing milk is a common practice in the dairy sector, especially in situations where the milk supply is limited, unstable, or affected by the season (Fava et al., 2014). For example, freezing was used by farmers in Wisconsin to reach sufficient quantities of ovine milk

Received February 24, 2020.

Accepted May 18, 2020.

*Corresponding author: eugenio.aprea@fmach.it before further processing (Wendorff et al., 2001). Another example is ewe milk from Greece that is mostly produced in spring, frozen, and used for yogurt production in summer and autumn (Katsiari et al., 2002). Furthermore, freezing can be applied to quality control activities to have a constant reference milk to verify whether the freshly produced milk meets certain quality standards. From a research perspective, freezing milk is particularly relevant to increase the flexibility and reproducibility of experiments: different milk samples can be stored until analysis, allowing all measurements to be run at one time with the same sample set. Nevertheless, researchers and experts in the dairy industry expressed skepticism about this practice, considering the possible adverse effects of freezing on milk stability (Needs, 1992).

When milk is frozen, several reactions occur, and it is important to distinguish those linked to the final freezing temperature from those related to the length of the frozen storage (Muir, 1984). Two major types of instability can emerge in milk upon freezing: fat separation, occurring when the milk undergoes the freezing process, and protein flocculation, which depends instead on the final storage temperature and length of the frozen storage. The literature lacks up-to-date data on the stability of these 2 milk components against freezing, especially the physicochemical nature of the modifications. The latest published articles dealt only with dairy products after prolonged frozen storage (de la Fuente et al., 1997; Katsiari et al., 2002; Tejada et al., 2002; Zhang et al., 2006); thus, a clear gap of knowledge on the response of milk to short-time freezing is evident (Muir, 1984).

In raw milk, lipids are present in the form of an emulsion stabilized by a milk fat globule membrane made up of protein and phospholipids (Truong et al., 2016). The freezing process damages the milk fat globule membrane, resulting in fat separation (Muir, 1984). This phenomenon is influenced by the cooling rate; 
it is generally believed that slow-rate freezing is more likely to cause separation of the fat globules (Webb and Hall, 1935). Eventually, these modifications of the fat fraction may produce an oxidized off-flavor (Zhang et al., 2006). The issue is minimized by homogenization because of the higher stability of the fat droplets with reduced size (Babcock et al., 1946; Herrera and Hartel, 2000). With regards to protein flocculation induced by freezing, caseins are the most sensitive fraction but require weeks at frozen conditions before becoming insoluble (Webb and Hall, 1935; Yamauchi et al., 1967).

The aim of this study was to clarify the relationship between freezing and milk stability by estimating the effect of a 72 -h slow- $\left(-20^{\circ} \mathrm{C}\right)$ and fast-rate $\left(-80^{\circ} \mathrm{C}\right)$ freezing on variables that commonly define the sensory qualities and physical properties of the milk. Limited freezing time was chosen to leave out any effects related to the length of the frozen storage, focusing only on phenomena happening during freezing and thawing.

Ultra-high-temperature hydrolyzed-lactose milk (UHLM) was chosen for the experiment. As the fat fraction is prone to freezing-induced changes, both low-fat (1\% fat) and whole-fat (3\% fat) UHLM from the same brand were considered. Three different commercial lots were analyzed in consideration of milk batch variability. High-density-polyethylene bottles $(1 \mathrm{~L})$ were stored at $20^{\circ} \mathrm{C}$ (control), $-20^{\circ} \mathrm{C}$ (slow-rate freezing), and $-80^{\circ} \mathrm{C}$ (fast-rate freezing). The freezing step lasted $72 \mathrm{~h}$. Immediately after, all samples were placed at $4^{\circ} \mathrm{C}$ for another $72 \mathrm{~h}$ for complete thawing. We opted for UHT milk because it is shelf stable, and consequently we expected no changes in the characteristics of the control sample during the $72 \mathrm{~h}$ at $20^{\circ} \mathrm{C}$, making the comparison of the frozen and unfrozen milk more realistic. Furthermore, we decided to test a lactose-free milk because of the emerging interest in this product category. In particular, many researchers pointed out higher instability of UHLM compared with regular UHT milk (Jansson et al., 2014a,b; Troise et al., 2016). On the other hand, lactose hydrolysis may also prevent protein destabilization when milk is frozen (Koschak et al., 1981).

Changes in the UHLM sensory quality were evaluated and focused on sensory properties, volatile organic compounds (VOC), and color. The triangle test (ISO, 2008) was chosen as the overall discriminant method for determining whether perceptible sensory differences exist among UHLM stored at different temperatures. The panel $(27 \%$ female and $73 \%$ male; age range $=23-62$ yr; mean age $=32.6 \mathrm{yr}, \mathrm{SD}=11.1$ ) consisted of employees and students at the Edmund Mach Foundation (San Michele all'Adige, Italy) and University of Trento (Trento, Italy) with previous records of participation in sensory tests. A total of 49 and 36 panelists took part in the 2 evaluation sessions, respectively. Of the judges, $91 \%$ had previous experience and training in discriminant analysis. Furthermore, $28 \%$ of them also had long-standing experience with descriptive tests. In each of these sessions, 3 consecutive triangle tests were carried out to compare the 3 UHLM by pairs: $20^{\circ} \mathrm{C}$ versus $-80^{\circ} \mathrm{C}, 20^{\circ} \mathrm{C}$ versus $-20^{\circ} \mathrm{C}$, and $-80^{\circ} \mathrm{C}$ versus $-20^{\circ} \mathrm{C}$. Tests were replicated in 2 separate sessions, one for each fat content, and in each session the 3 triangle tests were presented to panelists in a randomized order. For each storage treatment, UHLM from the 3 different commercial lots were mixed together. Then, $20 \mathrm{~mL}$ of milk was poured into transparent plastic-covered cups coded with a 3-digit random number and presented to the panelists in sensory booths under red light. The temperature of the samples was stabilized at $15^{\circ} \mathrm{C}$ before serving.

We analyzed VOC by headspace solid-phase microextraction gas-chromatography-MS. The procedure was previously optimized (Bottiroli et al., 2020). A 3-phasic (DVB-Carboxen-PDMS) solid phase microextraction fiber was used for the extraction step. The VOC were desorbed at $250^{\circ} \mathrm{C}$ in the injector port of a GC Clarus 500 (PerkinElmer, Norwalk, CT) interfaced with a mass detector operating in an electron ionization mode (internal ionization source; $70 \mathrm{eV}$ ) with a scan range from 33 to $300 \mathrm{~m} / z$. An HP-Innowax fused-silica capillary column $(30 \mathrm{~m}, 0.32 \mathrm{~mm}$ inner diameter, $0.5 \mu \mathrm{m}$ film thickness; Agilent Technologies, Palo Alto, CA) was used for the separation. Results were semiquantitative, highlighting trends in the VOC data.

Color changes were evaluated with a colorimeter (Minolta CM-3500d, Tokyo, Japan). The results were registered by the instrument in the CIELAB color system: $L^{*}$ (black: $L^{*}=0$ and white: $L^{*}=100$ ), $a^{*}$ (red-green: negative $\mathrm{a}^{*}=$ greenness and positive $\mathrm{a}^{*}=$ redness), and $b^{*}$ (yellow-blue: negative $b^{*}=$ blueness and positive $\mathrm{b}^{*}=$ yellowness). The instrument was internally calibrated with distilled water and an opaque material provided by the manufacturer. Measurements were performed in triplicate using quartz cells with a 1-cm optical path.

Changes in the UHLM physical stability were characterized by optical centrifugation, particle size analysis, and confocal laser scanning microscopy (CLSM). An LUMiFuge particle separation analyzer (LUM GmbH, Berlin, Germany) was used. Sample preparation and LUMiFuge settings followed the method reported by Zhang et al. (2020). Before analysis, the stored UHLM were diluted 10 times with simulated milk ultrafiltrate ( $\mathrm{pH}$ 6.8) to reduce the turbidity of low-fat and full-fat UHT milk to facilitate the optical measurement. The samples in LUMiFuge were centrifuged at $2,300 \times g$ for $43 \mathrm{~min}$ at room temperature, and the near-infrared 
transmission at a wavelength of $865 \mathrm{~nm}$ was measured every $10 \mathrm{~s}$. The integrated transmission percentage against time, which is referred to as the instability index, was used to quantify the emulsion stability of the samples. The instability index was automatically integrated with the LUMiFuge software SEPView 6.3. Higher instability index values indicate lower emulsion stability.

The mean particle diameter and the distribution of particle sizes in UHLM stored at different temperatures were determined in triplicate by laser light diffraction (Mastersizer 3000, Malvern Instruments Ltd., Malvern, UK). Samples diluted 50 times with MilliQ water (Millipore, Burlington, MA) were directly injected into the dispersion cell (containing MilliQ water) under agitation at $1,500 \mathrm{rpm}$. The refractive indices used in this study were 1.45 for the particles and 1.33 for the continuous phase (MilliQ water; Zhang et al., 2020). The particle absorption index was set as 0.002. The CLSM analyses were performed on UHLM stored at different temperatures to investigate the distribution of lipids and proteins, as previously described by Zhang et al. (2020).

The software packages Statistica 13.3 (StatSoft Inc., Tulsa, OK) and RStudio (RStudio Team, 2018, version 1.2.1335, RStudio: Integrated Development for R, RStudio Inc., Boston, MA) were used for the statistical analysis of the data. Triangle test outputs were collected and analyzed using FIZZ 2.46A software (Biosystemes, Couternon, France) and interpreted based on the ratio between the total number of responses and the minimum number of correct answers required to define an existing significant difference among the products (based on binomial distribution with $P=1 / 3$ ).

Explorative multivariate analysis of the VOC profiles was achieved by principal component analysis (PCA). Variables were previously mean centered and scaled to unit variance after log-transformation. We used ANOVA and Tukey posthoc tests to assess differences in $\operatorname{VOC}(P \leq 0.05)$, instability index $(P \leq 0.01)$, and mean sizes $(P \leq 0.01)$ between the samples stored at different temperatures. Color data were instead analyzed by the nonparametric Kruskal-Wallis test.

Results of the triangle tests showed that no overall difference among the UHLM was perceived by the panel for both low-fat (1\% fat) and whole-fat (3\% fat) milk (Table 1). Results were further confirmed by the similarity test: 5 out of the 6 triangle tests highlighted a similarity, showing that the difference between the frozen UHLM and the control was too small to be detectable. Triangle tests have been previously used to study the sensory perceived differences in milk due to packaging (Smet et al., 2009), proteolysis (Santos et al., 2003), and heat treatment (Pagliarini et al., 1990), but not to study the effect of short-time freezing on milk. Our results clearly demonstrated that the short freezing and thawing treatment did not alter the sensory properties; this evidence was further confirmed by the VOC and color analysis. In total, 25 VOC matched the mass spectra reported in the NIST and Wiley libraries, ranging between $<0.10$ and $15.95 \mu \mathrm{g} / \mathrm{L}$ of milk. The values, expressed as equivalents of internal standard, are summarized in Table 2. The detected VOC were already reported in other published studies on regular and hydrolyzed-lactose UHT milk (Jansson et al., 2014c; Troise et al., 2016; Bottiroli et al., 2020). Visualization of the VOC data was given by PCA. Figure 1 illustrates the score (Figure 1a) and loading plot (Figure 1b) of the first and second principal components, with an explained variance of $38.9 \%$ and $22.7 \%$, respectively. At a first glance, no changes due to freezing were detectable. The result was confirmed by the analysis of the variance: none of the VOC registered significant differences due to the applied storage treatments. Slow-rate freezing performed as well as fast-rate freezing, although previously considered more harmful for milk stability (Webb and Hall, 1935). Also, the instability of milk fat upon freezing, mentioned in earlier research (Webb and Hall, 1935; Muir, 1984), did not emerge as we could not detect particular trends in the VOC linked to fat oxidation. The spatial distribution of the PCA was primarily defined by the different fat content and the batch variability existing among the analyzed UHLM samples. A similar result was obtained from the color analysis. Overall, the combined results of the triangle tests, VOC profiling, and color analysis distinctly indicated that the sensory quality of low-fat and whole-fat UHLM is not altered by short-time freezing.

In addition, physical stability is a major concern for the dairy industry, especially because the demixing of nonskimmed UHT milk is difficult to judge visually due to the high turbidity (Zhang et al., 2020). Therefore, LUMiFuge was used to assess the stability behavior by recording the migration of particles under centrifugal forces. For both low- and whole-fat milk, no differences were observed in the instability index between the frozen UHLM and the ones stored at room temperature. Such a finding suggests that freezing at a slow rate $\left(-20^{\circ} \mathrm{C}\right)$ and fast rate $\left(-80^{\circ} \mathrm{C}\right)$ for $72 \mathrm{~h}$ has no negative effect on the sedimentation or creaming stability of UHLM. On the other hand, the instability indices of $1 \%$ fat UHLM were higher than those for $3 \%$ fat UHLM (Supplemental Figure S1, https://doi.org/10 $.3168 /$ jds.2020-18415), confirming the inverse relationship between the fat globule destabilization and the fat content of the milk (Lerche et al., 2003).

The effect of short-time freezing on the particle size was also investigated by means of laser light scattering 
Table 1. Results of the triangle tests performed to verify the effect of slow- $\left(-20^{\circ} \mathrm{C}\right)$ and fast-rate freezing $\left(-80^{\circ} \mathrm{C}\right)$ for $72 \mathrm{~h} \mathrm{on}$ the overall sensory perception of UHT hydrolyzed-lactose milk (UHLM)

\begin{tabular}{|c|c|c|c|c|c|}
\hline Treatment comparison $^{1}$ & $\begin{array}{c}\text { Fat } \\
\text { content }(\%)\end{array}$ & $\begin{array}{c}\text { Total } \\
\text { responses }\end{array}$ & $\begin{array}{c}\text { Correct } \\
\text { responses }\end{array}$ & $\begin{array}{c}\text { Difference } \\
\text { test }^{3}\end{array}$ & $\begin{array}{c}\text { Similarity } \\
\text { test }^{4}\end{array}$ \\
\hline \multirow[t]{2}{*}{$20^{\circ} \mathrm{C}$ vs. $-80^{\circ} \mathrm{C}$} & 1 & 49 & 13 & 0.8788 & 0.0002 \\
\hline & 3 & 36 & 11 & 0.6967 & 0.0002 \\
\hline \multirow[t]{2}{*}{$20^{\circ} \mathrm{C}$ vs. $-20^{\circ} \mathrm{C}$} & 1 & 49 & 11 & 0.9653 & 0.0005 \\
\hline & 3 & 36 & 11 & 0.8103 & $<0.0001$ \\
\hline \multirow[t]{2}{*}{$-80^{\circ} \mathrm{C}$ vs. $-20^{\circ} \mathrm{C}$} & 1 & 49 & 18 & 0.3565 & 0.1460 \\
\hline & 3 & 36 & 13 & 0.4225 & 0.0022 \\
\hline
\end{tabular}

${ }^{1}$ UHLM samples stored for $72 \mathrm{~h}$ at $20^{\circ} \mathrm{C},-80^{\circ} \mathrm{C}$, and $-20^{\circ} \mathrm{C}$, respectively.

${ }^{2}$ Correct responses are intended as number of panelists that correctly identified the odd sample in each triangle test.

${ }^{3}$ The column reported the $P$-value related to the error of type I $(\alpha)$ calculated by the difference test $(P<0.05)$ with FIZZ software $($ Biosystemes, Couternon, France).

${ }^{4}$ The column reported the $P$-value related to the error of type II $(\beta)$ calculated by the similarity test $(P<0.05)$ with FIZZ software $($ Biosystemes). The Pd (proportion of assessments with a detected difference between the 2 products) chosen was $37.5 \%$.

(Figure 2). The distributions of casein micelles overlapped with the fat globules, forming a pseudomonomodal size distribution for the control UHLM with
$1 \%$ and $3 \%$ fat content. This pseudomonomodal size distribution centered at approximately $0.2 \mu \mathrm{m}$, which is similar to the normal full-fat UHT milk (Zhang et al.,

Table 2. Volatile compound profile ( $\mu \mathrm{g} / \mathrm{L}$ of internal standard) of the analyzed UHT hydrolyzed-lactose milks; for each storage treatment, results are reported as the mean of 3 measurements performed on 3 different lots of production

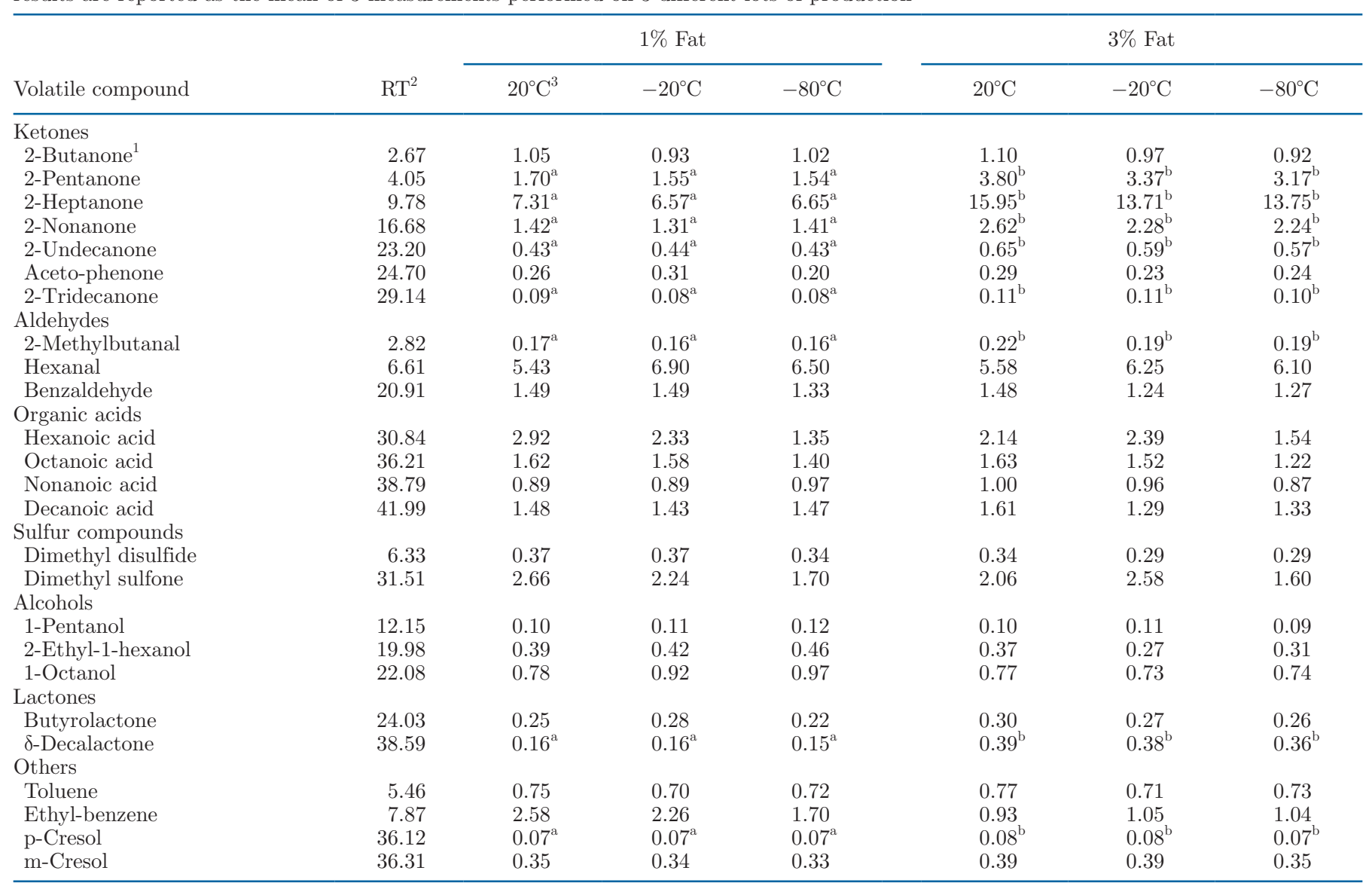

${ }^{\mathrm{a}, \mathrm{b}}$ Means within a row with different superscripts differ significantly $(P<0.05)$.

${ }^{1}$ Compounds tentatively identified matching the NIST-2014 and Wiley 7.0 libraries.

${ }^{2}$ Retention time expressed in minutes.

${ }^{3}$ All 3 storage treatments $\left(20^{\circ} \mathrm{C},-20^{\circ} \mathrm{C},-80^{\circ} \mathrm{C}\right)$ lasted $72 \mathrm{~h}$. 
2020). To further probe changes in size, we compared the surface-weighted mean particle diameter $(\mathbf{D})[3,2]$, which is sensitive to the presence of fine particulates, and the volume-weighted mean particle $\mathrm{D}[4,3]$, which is sensitive to the presence of large particulates in the size distribution. For $1 \%$ fat UHLM, freezing had no significant effect on the size distribution and the mean diameter. In $3 \%$ fat UHLM, some tiny peaks in the size range over $1 \mu \mathrm{m}$ appeared in the frozen samples, especially in those subjected to fast-rate freezing, as illustrated in the insert of Figure 2b. This indicated the formation of some larger aggregates. Accordingly, fastrate freezing $\left(-80^{\circ} \mathrm{C}\right)$ led to a slight increase in both $\mathrm{D}[3,2]$ and $\mathrm{D}[4,3]$ compared with the control milk and the slow-rate frozen milk $(P \leq 0.01)$. Because the effect appeared only in UHLM with $3 \%$ fat, these peaks were probably the result of fat destabilization. The effect is related to an increase in ice crystal size, resulting in less distance between the fat globules (Yanniotis, 2008). Hypothetically, at $-20^{\circ} \mathrm{C}$ part of the water was still unfrozen, whereas at $-80^{\circ} \mathrm{C}$ all water was present in the form of ice crystals, causing the partial coalescence of the fats.

The emulsion stability and the extent of droplets aggregation were also visualized by CLSM. The CLSM pictures of UHLM stored at all 3 temperatures were identical. Both the casein micelles and the fat globules were homogeneously distributed and had uniform size. No obvious aggregation was observed in the frozen samples and, overall, it cannot be concluded that freezing led to a profound effect on the microstructure and stability of UHLM.

When considering all of the results on the physical properties together, freezing for $72 \mathrm{~h}$ did not lead to destabilization of UHLM. It should be noted that in the fast-rate frozen samples, a slight tendency of aggregation was observed. Thus, freezing at $-80^{\circ} \mathrm{C}$ did not provide any benefits. As previously shown, milk proteins and fats may modify upon freezing. For the fat fraction, if destabilization arises, it is expected as soon as the milk undergoes the freezing. In this context, the final freezing temperature does not play a crucial role (Muir, 1984), but it is the physical state of the fat at the beginning of the freezing that matters. Key phenomena in this respect are the crystallization of milk fat and the size of the fat crystals (Jonkman et al., 1999). For example, when the freezing starts at refrigerated conditions, some crystals already exist and may grow excessively in size. The effect can pierce the fat globules and cause destabilization. In our study, the freezing started at room temperature and we can suppose that only small crystals were formed, contributing to the stability of the fat globules.

Destabilization of milk protein is influenced by other factors such as temperature, length of frozen storage, pre-treatments on the milk (e.g., concentration and heating), and modifications of the milk composition (Koschak et al., 1981). From our results, milk protein did not destabilize upon freezing, as the aggregates bigger than $1 \mu \mathrm{m}$ observed using the Mastersizer were related to fat destabilization. The protein fraction of the UHLM did not seem altered by the tested conditions, which is in line with the literature coupling the modifications of the protein to longer periods of frozen storage (Webb and Hall, 1935; Muir, 1984).

Koschak et al. (1981) reported that lactose hydrolysis may also prevent protein destabilization when milk is frozen. The soluble sugars, whose content is increased by the conversion of lactose, delay milk protein precipitation, maintaining their stability for longer periods
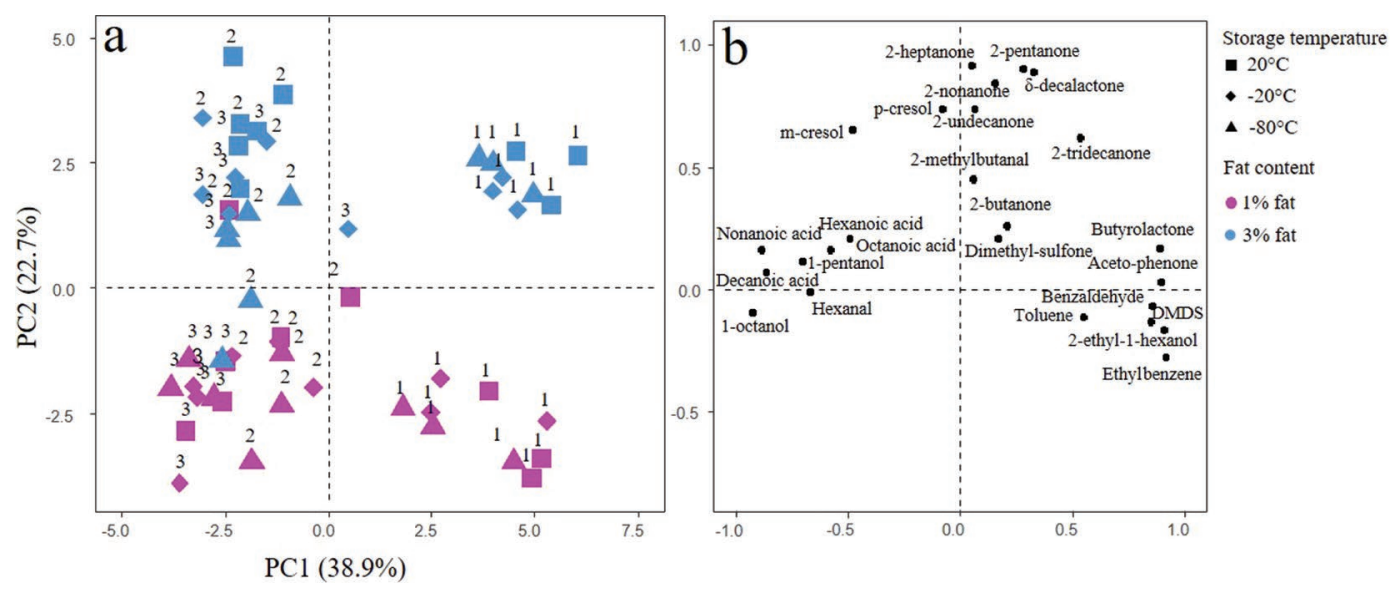

Figure 1. (a) Score plot of the principal component analysis (PCA) for the first (PC1) and second (PC2) principal components, accounting respectively for 38.9 and $22.7 \%$ of the total variance. The numbers 1,2 , and 3 indicate the commercial lots of each type of UHT hydrolyzedlactose milk samples (1\% and $3 \%$ fat). (b) Corresponding loading plot. DMDS = dimethyl disulfide. 

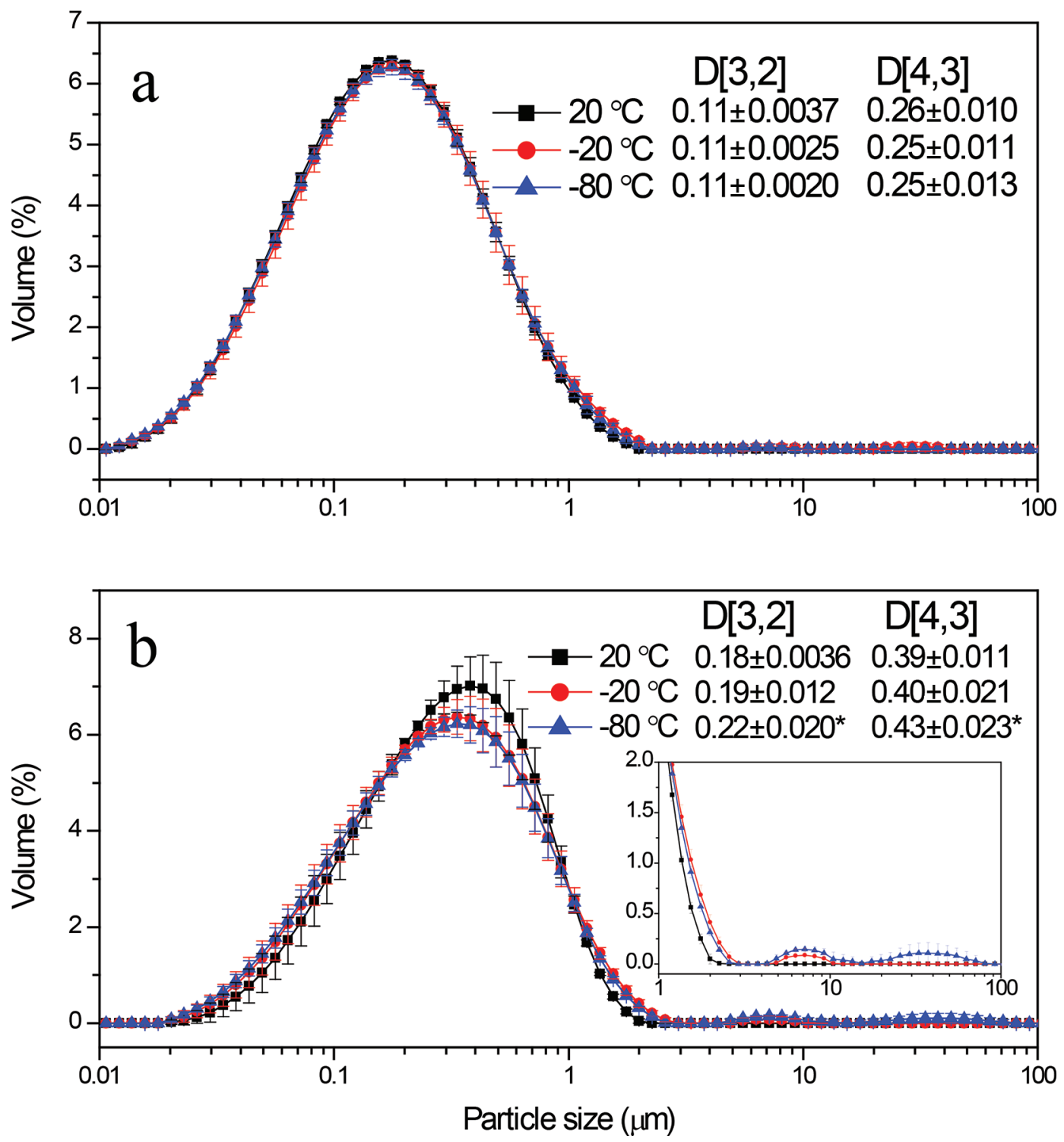

Figure 2. Volume-based particle size distribution, surface-weighted mean particle diameter (D)[3,2], and the volume-weighted mean particle diameter $\mathrm{D}[4,3]$ in UHT hydrolyzed-lactose milks with (a) $1 \%$ fat and (b) $3 \%$ fat stored at $20^{\circ} \mathrm{C},-20^{\circ} \mathrm{C}$, and $-80^{\circ} \mathrm{C}$ for $72 \mathrm{~h}$. The insert in panel b shows the size distribution higher than $1 \mu \mathrm{m}$ on an expanded scale. Data are presented as mean values of samples from 3 lots in triplicate; error bars represent SD. ${ }^{*} P<0.01$.

during frozen storage (Wells and Leeder, 1963). In our experiment, we can assume that the lactose hydrolysis played a role in keeping milk proteins stable, although such assumption will require further validation.

In conclusion, our research determined the stability of UHLM frozen for $72 \mathrm{~h}$ in terms of both sensory and physicochemical properties. According to the available literature, we initially expected that possible changes might occur in the fat fraction. Nevertheless, fat destabilization did not appear for low-fat or whole-fat milk. Homogenization was likely crucial in maintaining the fat fraction stability. Moreover, the velocity of freezing was not critical: similar results were obtained when the milk was exposed to slow- $\left(-20^{\circ} \mathrm{C}\right)$ and fast-rate freezing $\left(-80^{\circ} \mathrm{C}\right)$. Therefore, UHLM can be considered insensitive to alterations occurring during short freezing and thawing. This suggests addressing future research toward the phenomena occurring during frozen storage by a more comprehensive approach.

\section{ACKNOWLEDGMENTS}

The present study is part of the $\mathrm{PhD}$ project of Riccardo Bottiroli and financially supported by Wagenin- 
gen University (Wageningen, the Netherlands), Edmund Mach Foundation (San Michele all'Adige, Italy), and University Federico II of Naples (Portici, Italy). The authors greatly appreciate Thom Huppertz (Food Quality and Design Group, Wageningen University) for useful suggestions and general discussions on milk freezing. We also thank Leonardo Menghi (Department of Food Quality and Nutrition, Edmund Mach Foundation) for the support during the sensory sessions and all the panelists for their participation. The authors report no conflict of interest.

\section{REFERENCES}

Babcock, C. J., R. N. Roerig, J. N. Stabile, W. A. Dunlap, and R. Randall. 1946. Frozen homogenized milk. 1. Effect of freezing and storage temperature on the physical characteristics of homogenized milk. J. Dairy Sci. 29:699-706. https://doi.org/10.3168/jds .S0022-0302(46)92527-1.

Bottiroli, R., E. Aprea, E. Betta, V. Fogliano, and F. Gasperi. 2020. Application of headspace solid-phase micro-extraction gas chromatography for the assessment of the volatiles profiles of ultrahigh temperature hydrolysed-lactose milk during production and storage. Int. Dairy J. 107:104715. https://doi.org/10.1016/j.idairyj .2020 .104715 .

de la Fuente, A. M., T. Requena, and M. Juàrez. 1997. Salt balance in ewe's and goat's milk during storage at chilling and freezing temperatures. J. Agric. Food Chem. 45:82-88. https://doi.org/10 $.1021 / \mathrm{jf960388a}$.

Fava, L. W., I. C. Külkamp-Guerreiro, and A. T. Pinto. 2014. Evaluation of physico-chemical characteristics of fresh, refrigerated and frozen Lacaune ewes' milk. Arq. Bras. Med. Vet. Zootec. 66:19241930. https://doi.org/10.1590/1678-7675.

Herrera, M. L., and R. W. Hartel. 2000. Effect of processing conditions on physical properties of a milk fat model system: Microstructure. J. Am. Oil Chem. Soc. 77:1197-1205. https://doi.org/10.1007/ s11746-000-0186-2.

ISO (International Organization for Standardization). 2008. Sensory analysis-Methodology-Triangle test. ISO standard number 4120:2004. ISO, Geneva, Switzerland.

Jansson, T., M. R. Clausen, U. K. Sundekilde, N. Eggers, S. Nyegaard, L. B. Larsen, C. Ray, A. Sundgren, H. J. Andersen, and H. C. Bertram. 2014a. Lactose-hydrolyzed milk is more prone to chemical changes during storage than conventional ultra-high-temperature (UHT) milk. J. Agric. Food Chem. 62:7886-7896. https://doi.org/ 10.1021/jf501671z.

Jansson, T., H. B. Jensen, U. K. Sundekilde, M. R. Clausen, N. Eggers, L. B. Larsen, C. Ray, H. J. Andersen, and H. C. Bertram. 2014b. Chemical and proteolysis-derived changes during long-term storage of lactose-hydrolyzed ultrahigh-temperature (UHT) milk. J. Agric. Food Chem. 62:11270-11278. https://doi.org/10.1021/ jf504104q.

Jansson, T., S. Jensen, N. Eggers, M. R. Clausen, L. B. Larsen, C. Ray, A. Sundgren, H. J. Andersen, and H. C. Bertram. 2014c. Volatile component profiles of conventional and lactose-hydrolyzed UHT milk-A dynamic headspace gas chromatography-mass spectrometry study. Dairy Sci. Technol. 94:311-325. https://doi.org/10 .1007/s13594-014-0164-7.

Jonkman, M. J., P. Walstra, M. A. J. S. Van Boekel, and D. J. Cebula. 1999. Behaviour of casein micelles at conditions comparable to those in frozen yoghurt. Int. Dairy J. 9:385-386. https://doi.org/ 10.1016/S0958-6946(99)00099-0.

Katsiari, M. C., L. P. Voutsinas, and E. Kondyli. 2002. Manufacture of yoghurt from stored frozen sheep's milk. Food Chem. 77:413-420. https://doi.org/10.1016/S0308-8146(01)00367-3.

Koschak, M. S., O. Fennema, C. H. Amundson, and J. Y. Lee. 1981. Protein stability of frozen milk as influenced by storage tempera- ture and ultrafiltration. J. Food Sci. 46:1211-1217. https://doi .org/10.1111/j.1365-2621.1981.tb03025.x.

Lerche, D., L. Piesendel, and B. Senge. 2003. Characterization of food quality and structural stability by analytical centrifugation. Pages 149-153 in 3rd Int. Symp. Food Rheol. Struct. ETH Zürich, Zürich, Switzerland.

Muir, D. D. 1984. Reviews of the progress of dairy science: Frozen concentrated milk. J. Dairy Res. 51:649-664. https://doi.org/10 .1017/S0022029900032982.

Needs, E. C. 1992. Effects of long-term deep-freeze storage on the condition of the fat in raw sheep's milk. J. Dairy Res. 59:49-55. https://doi.org/10.1017/S0022029900030235.

Pagliarini, E., M. Vernile, and C. Peri. 1990. Kinetic study on color changes in milk due to heat. J. Food Sci. 55:1766-1767. https:// doi.org/10.1111/j.1365-2621.1990.tb03625.x.

Santos, M. V., Y. Ma, Z. Caplan, and D. M. Barbano. 2003. Sensory threshold of off-flavors caused by proteolysis and lipolysis in milk. J. Dairy Sci. 86:1601-1607. https://doi.org/10.3168/jds.S0022 -0302(03)73745-X.

Smet, K., J. De Block, S. De Campeneere, D. De Brabander, L. Herman, K. Raes, K. Dewettinck, and K. Coudijzer. 2009. Oxidative stability of UHT milk as influenced by fatty acid composition and packaging. Int. Dairy J. 19:372-379. https://doi.org/10.1016/ j.idairyj.2009.02.006.

Tejada, L., E. Sánchez, R. Gómez, M. Vioque, and J. Fernández-Salguero. 2002. Effect of freezing and frozen storage on chemical and microbiological characteristics in sheep milk cheese. J. Food Sci. 67:126-129. https://doi.org/10.1111/j.1365-2621.2002.tb11371.x.

Troise, A. D., E. Bandini, R. De Donno, G. Meijer, M. Trezzi, and V. Fogliano. 2016. The quality of low lactose milk is affected by the side proteolytic activity of the lactase used in the production process. Food Res. Int. 89:514-525. https://doi.org/10.1016/j.foodres 2016.08.021.

Truong, T., M. Palmer, N. Bansal, and B. Bhandari. 2016. An Overview of Milk Fat Globules. Springer International Publishing, Cham. Switzerland.

Webb, B. H., and S. A. Hall. 1935. Some physical effects of freezing upon milk and cream. J. Dairy Sci. 18:275-286. https://doi.org/10 .3168/jds.S0022-0302(35)93146-0.

Wells, P. R., and J. G. Leeder. 1963. Changes related to casein precipitation in frozen concentrated milk. J. Dairy Sci. 46:789-798. https: //doi.org/10.3168/jds.S0022-0302(63)89150-X.

Wendorff, W. L., Z. Rylqh, V. Plon, Z. D. V. Iur, H. Q. Dw, P. R. V. Shulrg, R. Zlwk, F. Uhvhdufkhuv, D. W. Wkh, G. Hwd, D. Q. G. Ohx, F. Iurp, R. Plon, G. Ghyhorsphqwdo, Z. Lq, and W. K. H. Xsshu. 2001. Freezing qualities of raw ovine milk for further processing. J. Dairy Sci. 84:E74-E78. https://doi.org/10.3168/jds .S0022-0302(01)70200-7.

Yamauchi, K., C. M. Chen, and T. Tsugo. 1967. Studies on destabilization of caseinate complex during frozen storage of milk. Agric. Biol. Chem. 31:581-599. https://doi.org/10.1080/00021369.1967 10858844

Yanniotis, S. 2008. Cooling and freezing. Pages 193-214 in Solving Problems in Food Engineering. Springer, New York, NY.

Zhang, C., E. Bijl, K. E. Muis, and K. Hettinga. 2020. Stability of fat globules in UHT milk during proteolysis by the AprX protease from Pseudomonas fluorescens and by plasmin. J. Dairy Sci. 103:179-190. https://doi.org/10.3168/jds.2019-17150.

Zhang, R. H., A. F. Mustafa, K. F. Ng-Kwai-Hang, and X. Zhao. 2006. Effects of freezing on composition and fatty acid profiles of sheep milk and cheese. Small Rumin. Res. 64:203-210. https://doi.org/ 10.1016/j.smallrumres.2005.04.025.

\section{ORCIDS}

R. Bottiroli (๑) https://orcid.org/0000-0003-2542-9762

C. Zhang $\odot$ https://orcid.org/0000-0002-9706-8129

E. Aprea (ㄴ) https://orcid.org/0000-0003-3648-0459

K. Hettinga @ https://orcid.org/0000-0002-9017-4447

F. Gasperi @ https://orcid.org/0000-0003-0055-9464 